\title{
GC-MS Analysis of Phyto-components from the Leaves of Senna alata $\mathrm{L}$
}

\author{
Omotoyinbo Oluwasegun Victor, Sanni Morakinyo David* \\ Department of Biochemistry, Federal University of Technology, Akure, Ondo State, Nigeria
}

Email address:

moraksanni@yahoo.co.uk (D. M. Sanni)

\section{To cite this article:}

Omotoyinbo Oluwasegun Victor, Sanni Morakinyo David. GC-MS Analysis of Phyto-components from the Leaves of Senna alata L. Journal of Plant Sciences. Vol. 3, No. 3, 2015, pp. 133-136. doi: 10.11648/j.jps.20150303.14

\begin{abstract}
The biochemical constituents of extracts obtained from the leaves of Senna alata obtained from Akure, Nigeria is being reported. The chloroform-methanol extracts was analysed by gas chromatography - mass spectrometry (GC-MS) techniques. The main constituents of the extracts were 6-Octadecenoic acid (24.99\%), 2, 3-Dihydroxypropyl-9-octadecenoate $(20.86 \%)$ and Octadecanoic acid $(18.08 \%)$.
\end{abstract}

Keywords: Senna alata, GC-MS, Ethnomedicine

\section{Introduction}

It has been assumed that "there is a plant for every need on every continent". Remarkably, this statement appears to be true. Finding healing powers in plants is an ancient idea [1]. The World Health Organization (WHO) estimates that $80 \%$ of the people living in developing countries almost exclusively use traditional medicine. Medicinal plants used in traditional medicine should therefore be studied for safety and efficacy. It has been estimated that $14-28 \%$ of higher plant species are used medicinally, which are only $15 \%$ of all angiosperms that have been investigated chemically. According to the database, $74 \%$ of pharmacologically-active plant derived drugs have been discovered after following up on ethnomedical use of the plant [2]. Naturally molecules derived from plant extracts offer a particularly exciting avenue for further research [3].

Senna alata L, (syn. Cassia alata L. Roxb.) is an erect tropical, annual herb with leathery compounded leaves. It belongs to the Fabaceae family. It grows up to about $8 \mathrm{~m}$ tall and can be found in diverse habitats. This perennial shrub has erect waxy yellow spikes that resemble fat candles before the individual blossoms open. The large leaves are bilateralsymmetrical opposed and fold together at night. The fruit is a pod, while the seeds are small and square $[4,5]$.

Senna alata has been reported to have very high medicinal values like antimicrobial property particularly against fungal dermatophytes and traditionally being used in the treatment of skin infections in man $[6,7]$. Leaf extract is a good antioxidant [7]. The juice of the fresh leaf of Senna alata is universally recognised as a remedy for parasitic skin diseases, and is used in many eruptive and pustular skin infections by simply rubbing the crushed leaves alone or mixed with lime juice or oil [8]. In Sierra Leone, the leaves in form of an infusion are used as a purgative, and a strong decoction is sometimes given as an abortifacent or during labour to hasten delivery, as the juice expressed from the fresh leaves is taken along with lime juice for worms [8]. With the numerous ethnomedicinal use of Senna alata leaf in different cultures and places, this study reveals the bioactive compounds present in Senna alata chloroform-methanol leaf extracts by GC-MS analysis.

\section{Materials and Methods}

\subsection{Collection of Plant and Preparation of Extract}

Senna alata plant leaves were obtained from Oba Ile area of Akure and confirmed by Herb sellers at Oja Oba market in Akure. Plant was later identified and authenticated at the Department of Crop Science, Federal University of Technology Akure, Ondo State Nigeria.

Shade dried leaves of Senna alata, were powdered and was extracted by the modified Bligh and Dyer procedure [9]. $5 \mathrm{~g}$ of powdered sample were shaken at room temperature with $18 \mathrm{ml}$ methanol-chloroform $(2: 1, \mathrm{v} / \mathrm{v})$ for 2 hours and filtered using cheese cloth. The residue obtained was further shaken with $18 \mathrm{ml}$ of methanol-chloroform $(2: 1, \mathrm{v} / \mathrm{v})$ and $2 \mathrm{ml}$ of water. This was followed by another round of filtration while 
the residue was also washed with $3 \mathrm{ml}$ of methanolchloroform $(2: 1 ; \mathrm{v} / \mathrm{v})$. The three filtrate obtained were combined in a separatory funnel with $5 \mathrm{ml}$ of chloroform and $6 \mathrm{ml}$ of water added and shaken before being allowed to separate into different phases. The chloroform layer was separated, diluted with benzene and concentrated. The residual lipids were immediately dissolved in $0.1 \mathrm{ml}$ chloroform-methanol (1:1) for analysis.

\subsection{GC-MS Analysis and Identification of Components}

The GC-MS analysis of Senna alata leaf oil extract was performed using a GC-MS QP2010 PLUS Shimadzu, Japan. Interpretation on mass spectrum of GC-MS was done using the database of National Institute Standard and Technology (NIST), having more than 62,000 patterns. The mass spectrum of the unknown component was compared with the spectrum of the known components stored in the NIST library. The name, molecular weight and structure of the components of the test materials were ascertained.

\section{Results and Discussion}

GC-MS chromatogram of the chloroform-methanol leaf oil extract of Senna alata (Figure 1) showed 11 peaks indicating the presence of eleven compounds. The chemical compounds identified in the extract of the leaf of Senna alata are presented in Table 1. The GC-MS analysis revealed that the presence of Methylpentadecanoate $(0.47 \%)$, n-Hexadecanoic acid (9.49\%), Methyloctadec-9-enoate (0.93 \%), 6Octadecenoic acid (24.99\%), Octadecanoic acid (18.08\%), Glycerol-1,3-dipalmitate (2.99 \%), 9-Octadecenoyl chloride (1.19\%), 9-Octadecenal (5.49\%), 3-Hydroxypropyl-9octadecanoate $(3.64 \%)$, 4-Dimethylsilyloxypentadecane (11.87 \%), 2,3-Dihydroxypropyl-9-octadecenoate (20.86\%).

The GC-MS analyses revealed that the lipid extract is mainly composed of esters and long chain fatty acids. Hexadecanoic acid has earlier been reported as the major component in leaf extract of Kigelia pinnata [10] and
Caralluma fimbriata [11]. Parasuraman et al., [12] also identified 17 compounds with n-Hexadecanoic acid and Octadecanoic acid as the major compounds in the leaves of Cleistanthus collinus. Esters and long chain fatty acids are constituents of plant resin and essential oils extracted from plants. Essential oils are volatile, natural, complex compounds characterized by a strong odour and are formed by aromatic plants as secondary metabolites [13]. In nature, essential oils play an important role in the protection of plants as antibacterial, antivirals, antifungals, insecticides and also against herbivores by reducing their appetite for such plants. They may also attract some insects, thereby favouring the dispersion of pollens and seeds, or repel other undesirable insects [13].Medical professionals are more interested in the medicinal properties of essential oils. Many oils show antibacterial, fungicidal, relaxant, stimulating, antidepressant effect and can be very effective therapeutic agent. Essential oils are known for their therapeutic properties hence, used in the treatment of various infections caused by both pathogenic and non-pathogenic diseases. Pathogenic diseases caused by bacterial, virus, and the fungi can be treated with essential oils [14]. Therefore the phytochemicals reported in this extract will account for the various pharmacological actions these plants part possess. So far, there is no study that can give a clear idea and be accurate on the mode of action of the essential oils. Given the complexity of their chemical composition, it is very likely that each of the constituents of the essential oils as obtained from Senna alata leaf has its own mechanism of action. Because of the variability of amounts and profiles of the components of essential oils, it is likely that their various medicinal activities is not due to a single mechanism, but to several sites of action at the cellular level and involving different modes of action. Thus, this type of GC - MS analysis is the first step towards understanding the nature of active principles in this medicinal plant and this type of study will be helpful for further detailed study in line with the biochemical and phytochemical functions mentioned above.

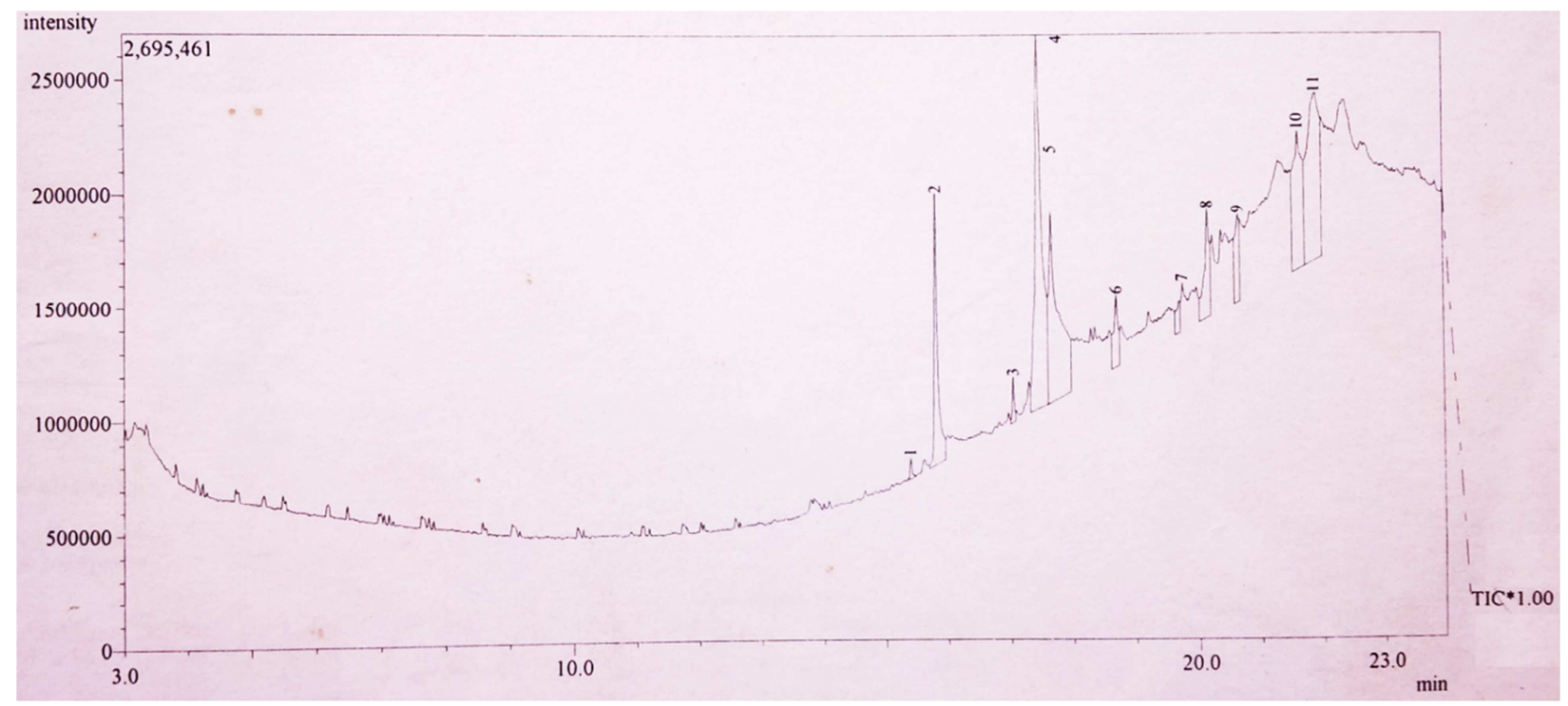

Figure 1. GC-MS Profile of chloroform-methanol leaves extract of Senna alata. 
Table 1. Bio-activity of phyto-components identified in the chloroform-methanol extracts of the leaf of Senna alata

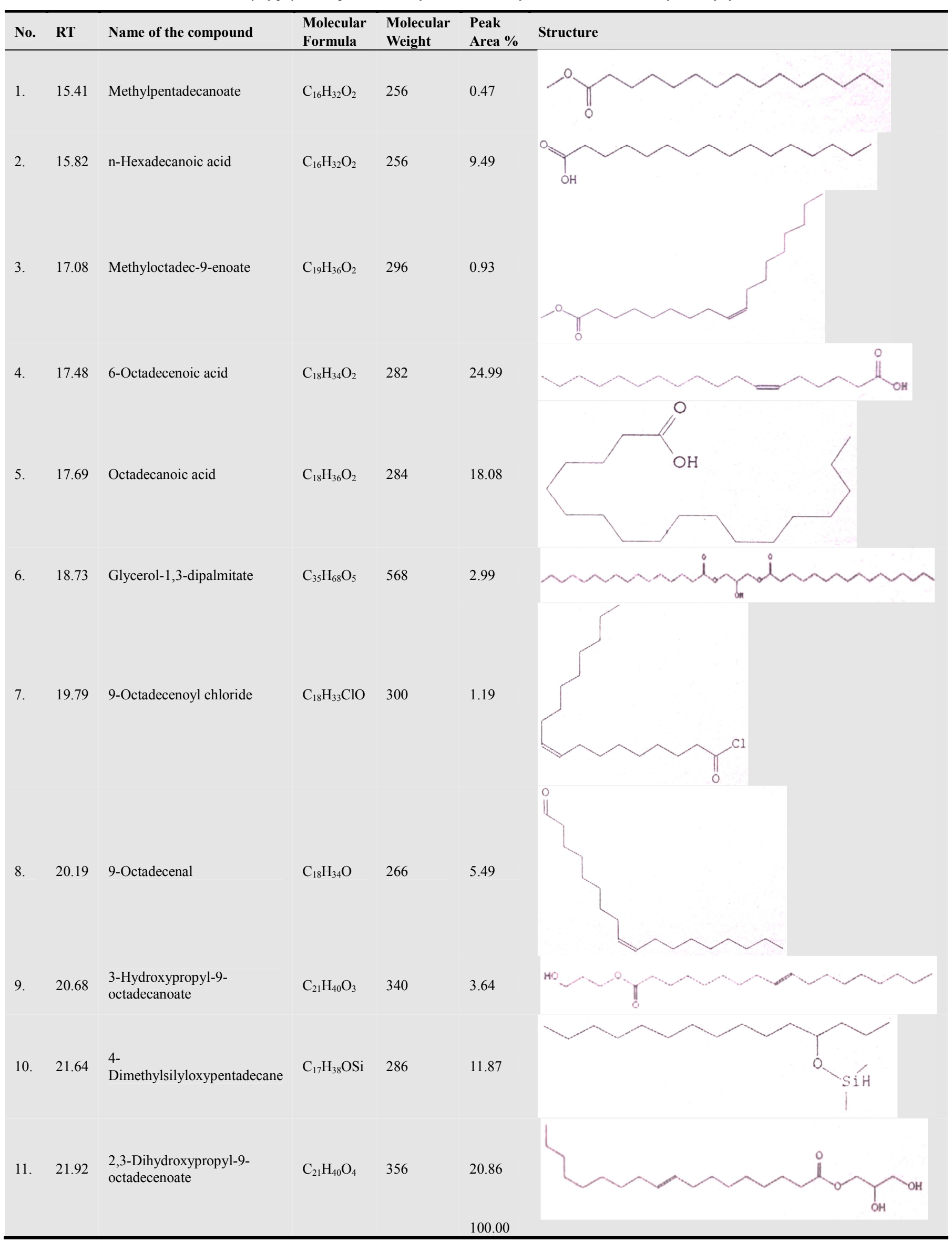




\section{References}

[1] Cowan, M. M. (1999). Plant products as Antimicrobial agents. Clinical Microbiology Reviews, 12(4): 564-582

[2] Eloff, J. N. (1998). Which extractant should be used for the screening and isolation of antimicrobial components from plants? Journal of Ethnopharmacology, 60: 1-8

[3] Aburjai T, Natsheh FM (2003). Plants used in Cosmetics. Phototherapy Research, 17: 98-1000

[4] Mabberly, D. J. (1987). The Plant-Book; A Portable Dictionary of Higher Plants. Cambridge University Press, Cambridge

[5] Ogunwande, I. A., Flamini, G., Cioni, P. L., Omikorede, O., Azeez, R. A., Ayodele, A. A., Kamil, Y. O. (2010). Aromatic Plants growing in Nigeria: Essential Oil Constituents of Cassia alata (Linn.) Roxb. and Helianthus annuus L. Records of Natural Products, 4(4): 211-217

[6] Igoli, J. O., Ogaji, O. G., Tor-Anyiin, T. A., Igoli, N. P. (2005). Traditional medicinal practices among the Igede people of Nigeria (part II). African Journal of Traditional Compliment Alternative Medicine, 2(2): 134-152

[7] Dutta, S., Chatterjee, S., Chatterjee, S. (2012). Overview on the ethnophytopathological studies of Cassia alata- an important medicinal plant and the effect of VAM on its growth and productivity. International Journal of Research in Botany, 2(4): $13-19$
[8] Igwe, O. U., Onwu, F. K. (2015). Leaf essential oil of Senna alata Linn from South East Nigeria and its Antimicrobial activity. International Journal of Research in Pharmacy and Chemistry, 5(1): 27-33

[9] Kates, M. (1978). The phytanyl ether-linked polar lipids and isoprenoid lipids of extremely halophilic bacteria. Prog. Chem. Fats Other Lipids, 15: 301-342

[10] Grace, O. M., Light, M. E., Lindsey, K. L., Moholland, D. A., Staden, J. V., Jader, A. K. (2002). Antibacterial activity and isolation of antibacterial compounds from fruit of the traditional African medicinal plant, Kigelia africana. South African Journal of Botany, 68: 220-222

[11] Priya, D., Rajaram, K., Suresh, K. P. (2011). Phytochemical studies and GC-MS analysis of Caralluma fimbriata wall. International Journal of Pharmaceutical Research and Development, 3(10): 105-110

[12] Parasuraman, S., Raveendran, R., Madhavrao, C. (2009). GCMS analysis of leaf extracts of Cleistanthus collinus Roxb. (Euphorbiaceae). International Journal of Pharmaceutical Science, 1(2):284-286.

[13] Abad, M. A., Bedoya, L. M., Apaza, L., Bermejo, P. (2012). The Artemisia L. Genus: a review of bioactive essential oils. Molecules, 17: 2542-2566.

[14] Hamid, A., Aiyelaagbe, O. O., Usman, L. A. (2011). Essential oils: Its medicinal and pharmacological uses. International Journal of Current Research, 3(2): 086-098. 